\title{
MANGROVE SEBAGAI BISNIS MASYARAKAT DI KAWASAN PESISIR
}

\section{MANGROVE AS A COMMUNITY BUSINESS IN THE COASTAL AREA}

\author{
Ismawati $^{1{ }^{*}}$, Eko Adi Sumitro, Rohman \\ Prodi Teknologi Hasil Pertanian, Universitas Wiraraja \\ Jl. Raya Sumenep-Pamekasan KM 5 Patean Sumenep \\ ismawati@wiraraja.ac.id
}

\begin{abstract}
Mangroves are found in coastal areas, growing between the sea and land affected by tides. Mangrove ecosystems grow along the coastline and have a special function because it is a community that tolerates salt. This study aims to determine the potential and types of mangroves that are used by coastal communities in the Prasional District. Alternative use of mangroves and analyzing economic value using purposive sampling method with 100 respondents using purposive sampling method in four locations and each population is chosen 10\%. Economic value and cost benefit analysis using descriptive methods and quantitative analysis with the cost benefit method. The results show that the mangrove ecosystem has high utilization as indicated by community income as the main income, household needs and traditional salt cultivation. Based on the balance between indicators for economic and ecological criteria following their utilization (100\% mangrove and 0\% monoculture) or ( $75 \%$ mangrove and $25 \%$ monoculture).
\end{abstract}

Keywords: economic, mangrove, value

\begin{abstract}
Abstrak
Mangrove terdapat diwilayah pesisir, tumbuh diantara laut dan daratan yang dipengaruhi oleh pasang surut air. Ekosistem mangrove tumbuh disepanjang garis pantai dan memiliki fungsi istimewa karena merupakan komunitas bertoleransi dengan garam. Penelitian ini bertujuan untuk mengetahui potensi dan jenis mangrove yang dimanfaatkan oleh masyarakat pesisir di daerah Kecamatan Pragaan. Alternatif pemanfaatan mangrove dan menganalisis nilai ekonomi menggunakan metode purposif sampling dengan 100 responden menggunakan metode purposive sampling di empat lokasi dan setiap populasi dipilih $10 \%$. Nilai ekonomi dan analisis manfaat biaya menggunakan metode deskriptif dan analisa kuantitatif dengan metode biaya manfaat. Hasil menunjukkan bahwa ecosistem mangrove memiliki pemanfaatan yang tinggi yang ditunjukkan oleh pendapatan masyarakat sebagai pendapatan utama, kebutuhan rumah tangga dan budidaya garam tradisional. Berdasarkan keseimbangan antara indikator untuk kriteria ekonomi dan ekologi mengikuti pemanfaatannya yaitu (100\% mangrove dan $0 \%$ monokultur) atau (75\% mangrove dan $25 \%$ monokultur)
\end{abstract}

Kata kunci: , Ekonomi, mangrove, nilai

\section{PENDAHULUAN}

Pesisir adalah pertemuan antara lautan dan daratan, baik kering maupun terendam. (Trinanda, 2017) menjelaskan definisi pesisir adalah wilayah yang tidak terpisahkan laut dan daratan karena Indonesia memiliki garis pantai. Wilayah pesisir memiliki beragam kekayaan seperti mineral, perikanan, ekosistem mangrove maupun dari segi pariwisata.

Maka menurut (Pramudyanto, 2014), dalam pengelolaan pesisir, perlu adanya kerangka kelembagaan yang jelas sehingga dapat mengembangkan kawasan 
pesisir. Permasalahan yang umum terjadi di kawasan pesisir yaitu pada hutan mangrove. Salah satu potensi pesisir Indonesia sebagai negara maritim yang memiliki pesisir kekayaan alam melimpah dan salah satu kekayaan alam yang perlu di eksplor adalah mangrove. Pengelolaan hutan mangrove merupakann salah satu modal untuk dapat mengoptimalkan pendapatan masyarakat pesisir (Kementrian kelautan dan Perikanan, 2017).

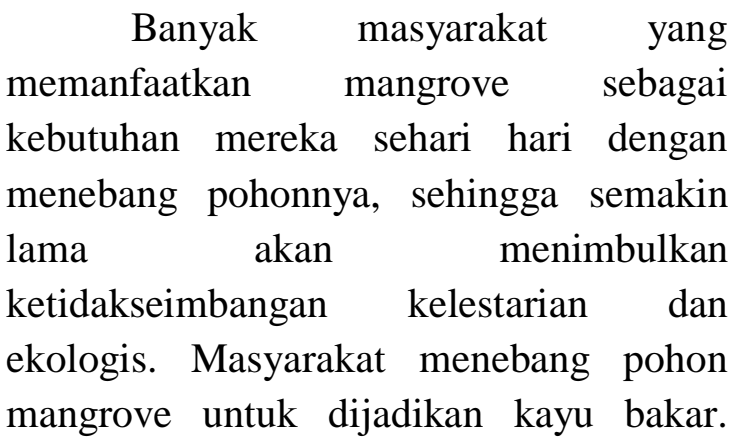
Semakin lama, kondisi penduduk meningkat pesat, dan berdampak pada pemukiman sepanjang kawasan pesisir sehingga dapat mengancam keberadaan dan keberlangsungan ekosistem mangrove. Dampak dari rusaknya keberlangsungan ekosistem magrove dapat menurunkan angka produksi biota laut yang hidup mereka bergantung pada mangrove. Dampak yang tak kalah penting yaitu timbulnya abrasi yang dapat mengakibatkan fungsi ekosistem mangrove mengalami gangguan.

Kawasan pesisir di Kabupaten Sumenep, yaitu kawasan sepanjang Kecamatan Pragaan, memiliki ekosistem mangrove dengan pemanfaatan yang sangat tinggi, jika dilihat berdasarkan dari luasan mangrove yang bermanfaat dalam menjaga lingkungan masyarakat supaya tidak terjadi abrasi, dan secara kualitas diukur melalui nilai kerugian yang dihasilkan, seperti halnya pemanfaatan mangrove sebagai bahan bangunan dan kayu bakar, dan konversi ke tambak garam.

Dalam kajian ini, permasalahan yang ada yaitu nilai ekonomi ekosistem mangrove dan bagaimana mengoptimalkan nilai ekonomis mangrove tanpa mengabaikan aspek ekologisnya. Tujuan penelitian ini menganalisis mangrove, srta pemanfataannya efektif dan efisien sehingga memberikan manfaat pengelolaan mangrove dengan mempertimbangkan aspek ekonomi dan aspek lingkungan.

Banyak manfaat mangrove yang belum banyak difahami oleh masyarakat pesisir baik secara langsung maupun tidak langsung. Mangrove juga berpotensi sebagai produk olahan pangan yang memiliki nilai tambah secara ekonomi (Sabana, 2014). Mangrove juga memiliki nilai ekonomi karbon sebagaimana yang dilaporkan (Kepel, Suryono, Nur Afi Ati, Salim, \& A. Hutahaean, 2017) bahwa nilai ekonomi karbon dari 8 spesies mangrove di Kecamatan Kema Sulawesi Utara berdasarkan pasar beba yaitu Rp. 6.955.123.566 pada luasan 174,92 ha. Kajian ini dilakukan untuk mengetahui nilai ekonomi mangrove secara langsung.

\section{METODE}

Penelitian ini dilakukan disepanjang kawasan pesisir kecamatan Pragaan pada bulan Agustus sampai November 2017. Pengumpulan data dengan pengamatan (survey) wawancara dan studi literatur. Data diperoleh dari data primer dengan wawancara kepada tokoh masyarakat pesisir sedangkan data 
sekunder diperoleh dari Instansi terkait seperti dinas perikanan.

Data dan informasi yang diperoleh dianalisis secara deskriptif dan kuantitatif. Tahapan penilaian ekonomi nilai mangrove terhadap bisnis, yaitu mengidentifikasi manfaat dan fungsifungsi keterkaitan komponen sumberdaya baik langsung, tidak langsung, pilihan dan manfaatnya terhadap pewaris. Kedua yaitu kuantifikasi manfaat dan fungsi terhadap nilai uang, dan pemanfaatan mangrove sebagai bisnis masyarakat pesisir Kecamatan Pragaan Kabupaten Sumenep.

\section{HASIL DAN PEMBAHASAN}

Berdasarkan pengamatan, dari survey maupun melalui wawancara dengan masyarakat pesisir menunjukkan bahwa ekosistem mangrove mengalami kerusakan. Kondisi mangrove sudah dikonversi menjadi tambak, dan harus diperhatikan dan mendapat perhatian yang serius karena menyangkut keberlangsungan ekosistem sumberdaya pesisir sehingga pengelolaannya harus terencana. Menurut (KAWAROE, 2001) menjelaskan ekosistem mangrove merupakan hal yang terpenting karena dapat memelihara keberadaan ekosistem dan dapat menunjang keberadaan biota menurut beberapa aspek yaitu fisik, biologi dan sosial ekonomi.

Tabel 1. Nilai Manfaat Langsung Mangrove

\begin{tabular}{llrrr}
\hline No & Jenis pemanfaatan & $\begin{array}{c}\text { Nilai } \\
\text { Manfaat } \\
(\mathbf{R p} / \mathbf{h a} / \mathbf{t h n}) \\
\mathbf{0 0 0}\end{array}$ & $\begin{array}{c}\text { Total Biaya } \\
\text { (Rp/ha/thn) } 000\end{array}$ & $\begin{array}{c}\text { Nilai Manfaat bersih } \\
\text { (Rp/ha/thn) } 000\end{array}$ \\
\hline $\mathbf{1}$ & Kayu & 2.625 & 0 & 2.625 \\
$\mathbf{2}$ & Tambak & 12.000 & 4.570 & 7.430 \\
$\mathbf{3}$ & Udang & 2.235 & 360 & 1.875 \\
$\mathbf{4}$ & Kepiting & 775 & 210 & 565 \\
\hline
\end{tabular}

Manfaat langsung dari ekosistem mangrove dapat diukur berdasarkan nilai kayu yang dapat dimanfaatkan untuk bahan bangunan atau kayu bakar, nilai dampak terhadap ekosistem perikanan ekonomis yaitu udang, ikan dan kepiting, dan nilai daun serta buah mangrove yang berupa nipah. Adapun manfaat tidak langsung meliputi fungsi mangrove sebagai penahan abrasi yang dikalkulasi berdasarkan replacement cost bangunan pemecah ombak (breakwater) serta manfaat pilihan yang menghitung manfaat keanekaragaman hayati ekosistem mangrove (Suzana et.al. dalam (Kepel et al., 2017)). Lebih lanjut (Ilham Marasabessy1, Achmad Fahrudin, 2018) memaparkan bahwa habitat di pesisir, terdapat campur tangan dan menyebabkan permasalahan/konflik internal dalam masyarakat, sehingga kebutuhan dan penyedia sumberdaya harus sesuai.

(Djunaedi, Basuki, \& Pada, n.d.) Masyarakat harus mengetahui kebijakan dan aturan untuk pemanfaatan kawasan pesisir terutama mangrove. Identifikasi mangrove pada vegetasi dimanfaatkan sebagai pertambakan udang alam kerang serta berbagai jenis ikan lainnya. Untuk pemanfaatan secara langsung pada kayu, ranting, penangkapan udang, kepiting serta ikan lainnya, dan juga sebagai tempat penangkapan burung, sebagaimana tercantum pada tabel 1 . 


\begin{tabular}{llrrr}
\hline $\mathbf{5}$ & Kerang & 1.104 & 420 & 684 \\
$\mathbf{6}$ & Ikan & 2.273 & 245 & 2.028 \\
$\mathbf{7}$ & Burung & 416 & 165 & 251 \\
& & & & 15.458 \\
\hline
\end{tabular}

Sumber: data olah primer

Tabel 1 menunjukkan pemanfaatan kayu sebagai sumber kehidupan, yaitu dipergunakan sebagai konstruksi rumah, kayu bakar dalam rumah tangga untuk memasak, dan berbagai aktivitas masyarakat lainnya, jika tidak segera diantisipasi akan menyebabkan kerusakan sumberdaya mangrove dan harus diberikan alternatif sebagai pengganti bahan tersebut. Lebih lanjut ekonomi mangrove secara langsung yang dilihat berdasarkan manfaat ikan dan kepiting sebesar 322.465.000/tahun (Kumaat, Pangemanan, \& Pangemanan, 2015).

Pemanfaatan mangrove yang dilakukan secara langsung dan tidak langsung. Pemanfaatan sebagai tambak, ataupun pada penangkapan biota ikan (udang, kepiting, kerang-kerangan dan berbagai jenis ikan) memiliki nilai manfaat tinggi. Berdasarkan pada Tabel 1 maka gga nilai total manfaat langsung dari ekosistem mangrove secara keseluruhan yaitu sebesar Rp. 1,069,095,000 per tahun.

Pada pemanfaatan mangrove secara tidak langsung diukur berdasarkan manfaat secara fisik dan biologis. Secara fisik, mangrove berfungsi sebagai penahan abrasi senilai Rp. 938,370,000 per tahun, sedangkan secara biologis mangrove sebagai sarana pembesaran, pemijahan dan penyedia pakan alami sebesar dengan nilai Rp 15,925,000. Adapun total nilai manfaat tak langsung sebesar Rp. 1,192,074,000 per tahun. Penelitian (Ariftia, Qurniati, \& Herwanti, 2014) menyebutkan bahwa nilai total manfaat tidak langsung dari hutan mangrove yaitu mencapai 1. 1.354.931.610 pertahun di Provinsi Nusa Tenggara Barat. Hasil analisis data kuantitatif dapat ditunjukkan pada tabel 2 .

Tabel 2. Nilai Total Ekonomi Ekosistem Mangrove

\begin{tabular}{|c|c|c|c|}
\hline No & Jenis Manfaat & $\begin{array}{c}\text { Nilai Manfaat } \\
\text { Bersih } \\
\text { (Rp/ha/tahun) } \\
\text { 000 } \\
\end{array}$ & $\begin{array}{l}\text { Total Nilai manfaat bersih } \\
\text { (Rp/tahun) } 000\end{array}$ \\
\hline \multicolumn{4}{|c|}{ Lahan bervegetasi mangrove } \\
\hline 1 & Manfaat Langsung & 15458 & 1004770 \\
\hline 2 & Manfaat tak langsung & 18336,6 & 1192074 \\
\hline 3 & Manfaat Pilihan & 135,263 & 8792,095 \\
\hline 4 & Manfaat Keberadaan & 525 & 34125 \\
\hline 5 & Manfaat Pewarisan & 800 & 52000 \\
\hline Lah & an Pertambakan & 2870 & 57400 \\
\hline Tot & & 38127,865 & 2291761,095 \\
\hline \multicolumn{4}{|c|}{ Sumber: data olah primer } \\
\hline man & $\begin{array}{c}\text { Berdasarkan tabel } 2 \text { maka } \\
\text { grove memberikan manfaat yang besar }\end{array}$ & $\begin{array}{l}\text { manusia } \\
\text { ditingkat }\end{array}$ & $\begin{array}{c}\text { sehingga pengelolaannya harus } \\
\text { secaraa maksimal serta }\end{array}$ \\
\hline
\end{tabular}


ekologi. Upaya peningkatan nilai total ekonomi bukan dengan perluasan tambak tetapi dengan peningkatan produktivitas dan dari pemanfaatan mangrove secara langsung seperti pemanfaatan buah dan daun sebagai produk olahan yang dapat meningkatlan nilai ekonomi.

Analisis manfaat biaya pada pemanfaatan lahan mangrove ditnjukkan pada tabel 3 .

Tabel 3. Hasil Analisis Manfaat Biaya pada Alternatif Pemanfaatan Lahan

\begin{tabular}{llrr}
\hline No & Alokasi Pemanfaatan & NPV $(\mathbf{R p})$ & B/C \\
\hline 1 & Nilai Manfaat Saat ini & $2,234,361,095$ & 8,59 \\
2 & Tanpa vegetasi Mangrove & $243,950,000$ & 2,81 \\
3 & 25\% Mangrove & $694,915,273$ & 3.78 \\
4 & $50 \%$ Mangrove & $1,267,855,548$ & 6.84 \\
5 & $75 \%$ Mangrove & $1,779,808,321$ & 8.47 \\
6 & $100 \%$ Mangrove & $2,291,761,095$ & 8.76 \\
\hline
\end{tabular}

Sumber: data olah primer

Hasil analisis biaya manfaat menunjukkan bahwa pemanfaatan ekosistem mangrove baik yang dikonversi maupun yang tidak dikonversi memberikan nilai NPV lebih dari satu. Hal ini menunjukkan bahwa layak untuk diusahakan. Pemanfaatan menurut kepentingan masyarakat pesisir dan stakeholder dengan ola umpangsari dengan $75 \%$ dan $25 \%$ sebagai alternatif pemanfaatan, karena dapat memberikan nilai ekonomi juga masih terjaga kelestariannya.

\section{KESIMPULAN}

Pengelolaan kawasan mangrove sebagai bisnis masyarakat pesisir dengan

\section{DAFTAR PUSTAKA}

Ariftia, R. I., Qurniati, R., \& Herwanti, S. (2014). Nilai Ekonomi Total Hutan Mangrove Desa Margasari Kecamatan Labuhan Maringgai Kabupaten Lampun Timur. Jurnal Silva Lestari, 2(3), 19-28.

Djunaedi, A., Basuki, N., \& Pada, P. (n.d.).

Perencanaan pengembangan kawasan pesisir, 225-231.

Ilham Marasabessy1, Achmad Fahrudin, Z. I. mempertahankan sistem tumpang sari, supaya menghasilkan nilai ekonomi yang besar dan relatif efisien. Selain itu dapat mengakomodir kepentingan ekonomi dan ekologi mangrove.

Berdasarkan potensi bisnis yang ada maka perlu diupayakan terciptanya bisnis berbasis mangrove pada masyarakat pesisir. Untuk mendukung intensifnya penjagaan ekosistem mangrove serta terwujudnya bisnis mangrove oleh masyarakat pesisir maka perlu peran aktif masyarakat khususnya masyarakat pada usia produktif dengan memberikan penyuluhan maupun pelatihan bisnis mangrove.

\& S. B. A. (2018). Strategi Pengelolaan Berkelanjutan Pesisir dan Laut Pulau Nusa Manu dan Pulau Nusa Leun di Kabupaten Maluku Tengah, 2(1), 1-22. KAWAROE, M. (2001). KONTRIBUSI EKOSISTEM MANGROVE TERHADAP STRUKTUR KOMUNITAS IKAN DI PANTAI UTARA KABUPATEN SUBANG, JAWA BARAT, 3 .

Kementrian kelautan dan Perikanan. Permen 
KP Nomor 63 Tahun 2017 tentang:

Rencana Strategis Kementerian kelautan

Tahun 2015 - 2019 (2017).

Kepel, T. L., Suryono, D. D., Nur Afi Ati, R., Salim, H. L., \& A. Hutahaean, A. (2017).

Nilai Penting Dan Estimasi Ekonomi

Simpanan Karbon Vegetasi Mangrove Di

Kecamatan Kema, Sulawesi Utara.

Jurnal Kelautan Nasional, 12(1), 19.

https://doi.org/10.15578/jkn.v12i1.6170

Kumaat, M. R., Pangemanan, L. R., \&

Pangemanan, P. A. Valuasi Ekonomi

Hutan Mangrove Di Desa Tiwoho

Kecamatan Wori Kabupaten Minahasa,

Fakultas Pertanian (2015).

Pramudyanto, B. (2014). Pengendalian

Pencemaran dan Kerusakan di Wilayah

Pesisir, (4), 21-40.

Sabana, C. (2014). Kajian Pengembangan

Produk Makanan Olahan Mangrove.

Jurnal Ekonomi Dan Bisnis, 14(01), 4046.

Trinanda, T. C. (2017). Pengelolaan Wilayah

Pesisir Indonesia dalam Rangka

Pembangunan Berbasis Pelestarian

Lingkungan, 75-84. 